\title{
Facilitators and barriers of stroke survivors in the early post-stroke phase
}

\author{
BEATRIX ALGURÉN ${ }^{1}$, ÅSA LUNDGREN-NILSSON ${ }^{1} \&$ \\ KATHARINA STIBRANT SUNNERHAGEN ${ }^{1,2}$ \\ ${ }^{1}$ Institute of Neuroscience and Physiology, Section of Clinical Neuroscience and Rehabilitation Medicine, \\ University of Gothenburg, Göteborg, Sweden and ${ }^{2}$ Sunnaas Rehabilitation Hospital and Medical Faculty, \\ Oslo University, Oslo, Norway
}

Accepted November 2008

\begin{abstract}
Purpose. To identify facilitators and barriers among persons with first-ever stroke discharged to the home in the first 3 months post-stroke by means of ICF categories.

Method. Stroke survivors were interviewed using semi-structured questions based on the ICF categories of Environmental factors of the Comprehensive ICF Core Set for Stroke (extended version) at 6 weeks and at 3 months post-stroke.

Results. The study sample exists of 67 stroke survivors with an average age of 71 years (51\% women). Eleven environmental factors from the ICF chapters 'support and relationship', 'products and technology' and 'services, systems and policies' were experienced to be facilitators and only 'physical geography' was experienced as a barrier by $50 \%$ or more of the participants in the study.

Conclusions. It was possible to document facilitators and barriers among stroke survivors in a structured way using ICF categories. The high number of experienced facilitators gives an idea of how well stroke care functions in Sweden. There is a great need for further studies examining environmental factors in the post-stroke phase.
\end{abstract}

Keywords: $I C F$, facilitators, barriers, stroke

\section{Introduction}

The sudden onset of disability following a stroke constitutes a major disruption to the continuity of a person's life experience [1]. Traditionally, most interventions focus on functional recovery and often do not consider the need for a return to life in the community and the ability to participate in life in a fulfilling way [2]. Because disability is viewed today in terms of the interaction between the individual and the environment [3-5], knowledge of environmental factors as facilitators or barriers is necessary to decelerate the disability creation process and accelerate the rehabilitation of patients. However, there is still little emphasis on the environment as a domain of intervention [6]. Studies with environmental objectives usually examine the impact of particular environmental factors. For example, it has been shown that the use of assistive devices has a strong impact on stroke survivors' daily activities $[7,8]$. Another example is the widely accepted but less studied impact of social support, which facilitates stroke outcome $[9,10]$. The best documented environmental factor in the context of stroke is possibly stroke unit care as a type of health care service [11]. There are a few measures for evaluating several aspects of the environment and not only single environmental factors. The Quality of the Environment (MQE) [6], the Craig Hospital Inventory of Environmental Factors (CHIEF) [12] and the Facilitators and Barriers Survey (FABS) [13] were developed to assess facilitators and barriers in people with a disability, particularly stroke. The measures comprise up to six environmental domains comparable 
with the five chapters of environmental factors in the International Classification of Functioning, Disability and Health (ICF) [4]: (1) products and technology; (2) natural environment and human made changes to environment; (3) support and relationships; (4) attitudes and (5) services, systems and policies. These five chapters are also represented in the extended version of the Comprehensive ICF Core Set for Stroke, which includes 37 environmental factors. The Comprehensive ICF Core Set for Stroke was developed to guide multidisciplinary assessments in patients with chronic stroke [14]. The extended version was amended with categories from the Core Set for patients with neurological conditions in acute hospital and early post-acute rehabilitation facilities $[15,16]$. As the natural pattern of recovery after stroke shows the greatest changes in the first 3 months $[17,18]$, knowledge about possible facilitators and barriers in this early period might contribute to making the recovery process more effective and preventing the disability creation process.

However, neither the three measures named above nor any others have been used to investigate facilitators and barriers in the early phase after acute stroke. As the ICF Core Set for Stroke was complemented with categories for the hospital period and early rehabilitation, it might be a good tool for examining the environmental influence of stroke survivors in this early phase.

The aim of this study was to identify facilitators and barriers among stroke survivors in the first 3 months after stroke by means of the environmental part of the Comprehensive ICF Core Set for Stroke (extended version). The specific aims were: (1) to document perceived facilitators and barriers among stroke survivors at 6 weeks and 3 months after stroke onset with ICF categories; and (2) to describe differences in environmental factors between persons who were discharged to the home at 6 weeks and persons who were discharged later than 6 weeks but within 3 months after stroke onset.

\section{Methods}

\section{Participants}

The study sample consisted of 67 patients from four stroke units at Sahlgrenska University Hospital, Göteborg. Patients were recruited from February to July 2006 with the inclusion criteria of a diagnosis of first-ever stroke (ICD-10 codes I60-I67), age of at least 18 years and ability to give informed consent. Patients with severe speech problems or cognitive impairment were excluded. Stroke was clinically determined by specialists at the stroke units according to the World Health Organization (WHO) criteria [19] and confirmed by computed tomography (CT).
Variables

The appraisal of facilitators and barriers was carried out with the environmental part of the extended version of the Comprehensive ICF Core Set for Stroke. The Comprehensive ICF Core Set is a list of ICF categories that are assumed to be of importance in most of stroke survivors [14]. It was amended with categories from the Core Set for patients with neurological conditions in the acute hospital and in early post-acute rehabilitation facilities $[15,16]$ in the scope of the international WHO Collaboration Project to validate ICF Core Sets [20]. This extended version of the Core Set comprises 166 ICF categories of which 37 are environmental categories. Eight categories belong to the chapter 'products and technology', three categories to 'natural environment and human-made changes to environment', seven categories to 'support and relationships', nine categories to 'attitudes' and 10 categories to 'services, systems and policies'. The qualifier scale proposed by the WHO [5] was used to evaluate the extent of facilitators or barriers in the person's environment. The proposed scale has nine response categories ranging from -4 to +4 : a mild/ moderate/severe/complete barrier $(-1$ to -4$)$, a mild/moderate/substantial/complete facilitator (1 to 4 ), or no influence (0) on the patient's life. A further two response options are available: ' 8 - not specified' and ' 9 - not applicable'. The latter are used when a category is not applicable in a determinate patient or situation. For example, if an individual has no friends, the category 'e 320 friends' is not applicable. Response option ' 8 - not specified' is used when available information does not suffice to quantify the severity of the problem and/or is ambiguous (e.g. in interviews with participants with slight communication problems).

The modified Rankin Scale (mRS) was used to assess disability/stroke severity. The $\mathrm{mRS}$ is a commonly used scale (ranging from ' $0=$ no symptoms at all' to ' $6=$ dead') to describe disability in stroke survivors [21]. The intra-reliability of $\mathrm{mRS}$ is good, with a kappa above 0.80 [22].

Overall health-related quality of life (HRQoL) was measured using the visual analogue scale (VAS) from the Euroqol-5D (EQ-5D), ranging from ' $0=$ worst imaginable health state' to ' $100=$ best imaginable health state' $[23,24]$.

\section{Data collection procedures}

A contact person (nurse/physiotherapist) working at each stroke unit informed the research assistant about new admissions on a weekly basis. Eligible stroke patients were seen for recruitment within the 
first week after admission (T0). Patients were provided with a written description of the study, and in the case of participation, written informed consent was obtained. Demographic information, overall HRQoL and stroke severity (mRS), as well as subtype and side of stroke (both determined by a stroke specialist), were recorded. Participants were followed up at 6 weeks (T1) and 3 months (T2) poststroke, either at home or in the hospital. They were interviewed using semi-structured questions based on the environmental part of the extended version of the Comprehensive ICF Core Set for Stroke. All interviews were conducted by the same research assistant who is trained in the scope of the international WHO Collaboration Project to validate ICF Core Sets [20]. Semi-structured questions were for example as follows: What do you think about the general social support services? How do your family and friends handle the new situation; are you getting help? How do you experience the rehabilitation services? How do you experience your housing situation; have any adaptations been made? Are you able to go outside and meet other people? The last question was: Is there anything that helps or hinders you that you have not yet mentioned? If anything was mentioned as a facilitator or a barrier, the participants were asked the magnitude (mild/moderate/ substantial/complete) to which it was a facilitator or a hinder. In addition to the semi-structured questions, participants were asked to grade their health status on the VAS of the EQ-5D at each interview.

The study was approved by the ethics committee of Göteborg University.

\section{Data analysis}

As the aim of this study was to identify the presence or absence of facilitators and barriers (not the extent), the degrees of the qualifier scale were reduced to categorical data as follows: qualifiers 1 to 4 were recoded to 1 (facilitator), qualifiers -1 to -4 were recoded to -1 (barrier), the response option ' 8 - not specified' was handled as a missing, and qualifiers 0 (neither/nor) and 9 (not applicable) were maintained. Univariate statistics were used to describe the sample characteristics and examine the frequency of facilitators and barriers. When the variables were not normally distributed (KolmogorovSmirnov test [25]), medians are reported. To investigate differences in subgroups, the $t$-test (or in the case they were not normally distributed, the $U$-test) was used for continuous variables and the Chi-square test was used for proportions. The Sign test was used to investigate changes between the $\mathrm{T} 1$ and T2. All tests were carried out two-sided at local alpha levels of 5\%. Statistical analyses were made with SPSS (Version 13.0).

\section{Results}

\section{Description of the participants}

All of the 67 participants ( $51 \%$ women) were discharged to the home within 3 months of stroke onset. Forty-nine $(73 \%)$ of the 67 participants were already at home 6 weeks after stroke onset and are called early home (EH) participants ( $51 \%$ women). The 18 (27\%) participants who were discharged later are called late home (LH) participants (50\% women).

The participants had an average age of 71 years; women were significantly older than men. The main cause of stroke was cerebral infarction $(84 \%)$. At admission, the participants had an average mRS score of 3 (range 1-5); at 6 weeks and 3 months, the participants scored an average of 2. LH participants scored significantly higher than EH participants at all time points. At 3 months, women scored significantly higher than men. The overall HRQoL of the participants had mainly increased between admission and 6 weeks after stroke onset, from 58 to 69 (range 0-100). LH participants had a significantly lower HRQoL than $\mathrm{EH}$ participants at 6 weeks, and women had a significantly lower HRQoL than men at 3 months. The baseline characteristics and diagnoses in the study sample are shown in Table I, stratified by sex and discharge group (EH and $\mathrm{LH}$ participants).

\section{Environmental factors}

The stated facilitators and barriers of half or more of the participants were able to be documented with 11 ICF categories as facilitators and one category as a barrier. Family, as well as friends, colleagues and neighbours, were facilitators for almost all participants, as were medications (included in e110 products and substances for personal consumption). The feature of land forms such as hills (including in e210 - physical geography) was the one barrier that was a hinder in half of the participants. Otherwise, only individual people perceived medicine (e110), assistive devices such as walking frame or wheelchair (e120), extended family (e315), health professionals (e355) and health services, systems and policies (e580) as barriers. The barrier of physical geography was significantly more common at 3 months than at 6 weeks, whereas the individual attitudes of health professionals were perceived significantly less often as being facilitators at 3 months than they were at 6 weeks. 
Table I. Baseline characteristics of the study participants.

\begin{tabular}{|c|c|c|c|c|c|}
\hline & \multicolumn{2}{|c|}{ Sex } & \multicolumn{2}{|c|}{ Discharge group } & \multirow[b]{2}{*}{ Total $(N=67)$} \\
\hline & Men $(n=33)$ & Women $(n=34)$ & $\mathrm{EH}(n=49)$ & $\mathrm{LH}(n=18)$ & \\
\hline Age, mean $(\min -\max )$ & $67(35-85)$ & $75.7(26-94)^{\star}$ & $71.8(26-94)$ & $70.4(45-88)$ & $71.4(26-94)$ \\
\hline \multicolumn{6}{|l|}{ Diagnose ICD 10} \\
\hline I61 & 15.2 & 5.9 & 10.2 & 11.1 & 10.4 \\
\hline I63 & 78.8 & 88.2 & 81.6 & 88.9 & 83.6 \\
\hline I64 & 6.1 & - & 4.1 & - & 3.0 \\
\hline Others (I67) & - & 5.9 & 4.1 & - & 3.0 \\
\hline \multicolumn{6}{|l|}{ Localisation } \\
\hline Left & 36.4 & 38.2 & 34.7 & 44.4 & 37.3 \\
\hline Right & 27.3 & 17.6 & 26.5 & 11.1 & 22.4 \\
\hline Ambilateral & 3 & 5.9 & 6.1 & - & 4.5 \\
\hline Central & 12.1 & 8.8 & 6.1 & 22.2 & 10.4 \\
\hline Unspecified & 21.2 & 29.4 & 26.5 & 22.2 & 25.4 \\
\hline \multicolumn{6}{|c|}{ Overall HRQoL, mean (min-max) } \\
\hline T0 & $64(20-100)$ & $53(20-100)$ & $60(20-100)$ & $56(20-85)$ & $58(15-100)$ \\
\hline $\mathrm{T} 1$ & $73(30-95)$ & $71(40-95)$ & $74(40-95)$ & $60(30-85)^{\star}$ & $69(30-95)$ \\
\hline $\mathrm{T} 2$ & $77(40-100)$ & $68(30-95)^{\star}$ & $73(40-100)$ & $69(30-85)$ & $71(30-100)$ \\
\hline \multicolumn{6}{|c|}{ Rankin Scale, median (min-max) } \\
\hline T0 & $3(1-5)$ & $3(1-5)$ & $3(1-4)$ & $4(3-5)^{\dagger \dagger}$ & $3(1-5)$ \\
\hline $\mathrm{T} 1$ & $2(0-4)$ & $2(1-4)$ & $2(0-4)$ & $3(2-4)^{\dagger \dagger}$ & $2(0-4)$ \\
\hline $\mathrm{T} 2$ & $1(0-4)$ & $2(0-4)^{\dagger}$ & $2(0-4)$ & $3(2-4)^{\dagger}$ & $2(0-4)$ \\
\hline
\end{tabular}

$\mathrm{EH}$, early home participants; LH, late home participants.

${ }^{\star} p<0.05,{ }^{\star \star} p<0.001$ (t-test); ${ }^{\dagger} p<0.05,{ }^{\dagger} p<0.001$ (U-test).

At 6 weeks, it was significantly more common for $\mathrm{LH}$ participants to indicate assistive devices for mobility (e120), and health professionals and their attitudes (e355 and e450) as facilitators than $\mathrm{EH}$ participants. There were no significant differences at 3 months. The most frequent facilitators and barriers at 6 weeks and at 3 months are shown in Table II, stratified by discharge groups $-\mathrm{EH}$ and $\mathrm{LH}$ participants.

\section{Discussion}

In this study, we identified frequent facilitators and barriers indicated by stroke survivors at 6 weeks and 3 months after stroke onset and documented them with ICF categories. Overall, half or more of the participants perceived $11 \mathrm{ICF}$ categories as facilitators (mainly family and friends, but also social security and health services). The hilly physical geography was the only category that was perceived by about half of the participants as a barrier. Otherwise, only individual people perceived the frequent facilitators as barriers. Physical geography was more commonly mentioned as a barrier, whereas the attitudes of health professionals were stated less commonly as a facilitator at 3 months than at 6 weeks. One specific aim of this study was to investigate environmental differences as stated by the $\mathrm{EH}$ and $\mathrm{LH}$ participants. It could be seen that statements concerning facilitators and barriers were influenced by the different situations of the $\mathrm{EH}$ and LH participants. At 6 weeks, the LH participants were still in hospital and named more often than $\mathrm{EH}$ participants (who were already discharged to the home), health professionals and services as facilitators. Likewise, the LH participants (who were more disabled than the $\mathrm{EH}$ participants) stated more often assistive devices as facilitators.

By using ICF categories, it was possible to document the 11 facilitators and the one barrier in a structured way. The extent to which a category was a facilitator or a hinder was not examined.

The participants in our study spoke mainly of facilitators. They perceived the provided medicine and, if necessary, walking devices, wheelchairs or other assistive products for personal use in daily living primarily as being facilitators. Furthermore, they described family, friends and health professionals, and health professionals' attitudes to be supportive. They also stated that, in their situation as stroke patients, health and social services had functioned well up to the time at which they were interviewed. These overall positive statements may be surprising but might be explained by our having included only patients from stroke units. Organised inpatient (stroke unit) care in Sweden emphasises the European Stroke Strategies, which have a minimum of seven criteria, among them a dedicated team with a stroke physician, trained nurses, physiotherapists 
Table II. Frequent facilitators and barriers in ICF terms at 6 weeks and 3 months after stroke onset.

\begin{tabular}{|c|c|c|c|c|c|c|c|c|}
\hline \multirow[b]{2}{*}{ ICF code } & \multirow[b]{2}{*}{ ICF category title } & & \multicolumn{3}{|c|}{ At 6 weeks } & \multicolumn{3}{|c|}{ At 3 months } \\
\hline & & & $\mathrm{EH}(n=49)$ & $\mathrm{LH}(n=18)$ & Total $(n=67)$ & $\mathrm{EH}$ & LH & Total \\
\hline \multicolumn{9}{|c|}{ Chapter 1 Products and technology } \\
\hline \multirow[t]{3}{*}{ e110 } & \multirow{3}{*}{$\begin{array}{l}\text { Products or substances } \\
\text { for personal } \\
\text { consumption }\end{array}$} & Facilitator & $44(89.8)$ & $17(94.4)$ & $61(91)$ & $44(91.7)$ & $17(94.4)$ & $61(92.4)$ \\
\hline & & Neither/nor & $5(10.2)$ & - & $5(7.5)$ & $3(6.3)$ & $1(5.6)$ & $4(6.1)$ \\
\hline & & Barrier & - & $1(5.6)$ & $1(1.5)$ & $1(2.1)$ & - & $1(1.5)$ \\
\hline \multirow[t]{4}{*}{ e120 } & \multirow{4}{*}{$\begin{array}{l}\text { Products and technology } \\
\text { for personal indoor and } \\
\text { outdoor mobility and } \\
\text { transportation }\end{array}$} & Facilitator & $21(42.9)$ & $13(72.2)^{\star}$ & $34(50.7)$ & $25(52.1)$ & $14(77.8)$ & $39(59.1)$ \\
\hline & & Neither/nor & $1(2)$ & $2(11.1)$ & $3(4.5)$ & - & - & - \\
\hline & & Barrier & - & - & - & $1(2.1)$ & - & $1(1.5)$ \\
\hline & & Not applicable & $27(55.1)$ & $3(16.7)$ & $30(44.8)$ & $22(45.8)$ & $4(22.2)$ & $26(39.4)$ \\
\hline \multirow[t]{3}{*}{ e125 } & \multirow{3}{*}{$\begin{array}{l}\text { Products and technology } \\
\text { for communication }\end{array}$} & Facilitator & $31(70.5)$ & $9(52.9)^{\star}$ & $40(65.6)$ & $12(63.2)$ & $6(50)$ & $18(58.1)$ \\
\hline & & Neither/nor & $12(27.3)$ & $4(23.5)$ & $16(26.2)$ & $6(31.6)$ & $4(33.3)$ & $10(32.2)$ \\
\hline & & Not applicable & $1(2.3)$ & $4(23.5)$ & $5(8.2)$ & $1(5.3)$ & $2(16.7)$ & $3(9.7)$ \\
\hline \multicolumn{9}{|c|}{ Chapter 2 Natural environment and human-made changes to environment } \\
\hline \multirow[t]{3}{*}{ e210 } & \multirow[t]{3}{*}{ Physical geography } & Neither/nor & $27(55.1)$ & $5(27.8)$ & $32(47.8)$ & $25(51)$ & $6(33.3)$ & $31(46.3)$ \\
\hline & & Barrier & $21(42.9)$ & $5(27.8)^{\star \star}$ & $26(38.8)$ & $24(49)$ & $11(61.1)$ & $35(52.2)$ \\
\hline & & Not applicable & $1(2)$ & $8(44.4)$ & $9(13.4)$ & - & $1(5.6)$ & $1(1.5)$ \\
\hline \multicolumn{9}{|c|}{ Chapter 3 Support and relationships } \\
\hline \multirow[t]{3}{*}{ e310 } & \multirow[t]{3}{*}{ Immediate family } & Facilitator & $47(95.9)$ & $17(94.4)$ & $64(95.5)$ & $48(98)$ & $18(100)$ & $66(98.5)$ \\
\hline & & Neither/nor & $2(4.1)$ & $1(5.6)$ & $3(4.5)$ & - & - & - \\
\hline & & Not applicable & - & - & - & $1(2)$ & - & $1(1.5)$ \\
\hline \multirow[t]{4}{*}{ e315 } & \multirow[t]{4}{*}{ Extended family } & Facilitator & $45(91.8)$ & $17(94.4)$ & $62(92.5)$ & $46(93.9)$ & $15(83.3)$ & $61(91)$ \\
\hline & & Neither/nor & $1(2)$ & - & $1(1.5)$ & - & $1(5.6)$ & $1(1.5)$ \\
\hline & & Barrier & - & $1(5.6)$ & $1(1.5)$ & - & $1(5.6)$ & $1(1.5)$ \\
\hline & & Not applicable & $3(6.1)$ & - & $3(4.5)$ & $3(6.1)$ & $1(5.6)$ & $4(6)$ \\
\hline \multirow[t]{3}{*}{ e320 } & \multirow[t]{3}{*}{ Friends } & Facilitator & $42(85.7)$ & $14(93.3)$ & $56(87.5)$ & $41(83.7)$ & $14(77.8)$ & $55(82.1)$ \\
\hline & & Neither/nor & $3(6.1)$ & - & $3(4.7)$ & - & $1(5.6)$ & $1(1.5)$ \\
\hline & & Not applicable & $4(8.2)$ & $1(6.7)$ & $5(7.8)$ & $8(16.3)$ & $3(16.7)$ & $11(16.4)$ \\
\hline e325 & Acquaintances, peers, & Facilitator & $42(85.7)$ & $14(93.3)$ & $56(87.5)$ & $42(85.7)$ & $14(77.8)$ & $56(83.6)$ \\
\hline & colleagues, neighbours & Neither/nor & $3(6.1)$ & - & $3(4.7)$ & - & $1(5.6)$ & $1(1.5)$ \\
\hline & $\begin{array}{l}\text { and community } \\
\text { members }\end{array}$ & Not applicable & $4(8.2)$ & $1(6.7)$ & $5(7.8)$ & $7(14.3)$ & $3(16.7)$ & $10(14.9)$ \\
\hline e355 & Health professionals & Facilitator & $29(60.4)$ & $18(100)^{\star}$ & $47(71.2)$ & $22(44.9)$ & $14(77.8)$ & $36(53.7)$ \\
\hline & & Neither/nor & $1(2.1)$ & - & $1(1.5)$ & $1(2)$ & - & $1(1.5)$ \\
\hline & & Barrier & - & - & - & $2(4.1)$ & - & $2(3)$ \\
\hline & & Not applicable & $18(37.5)$ & - & $18(27.3)$ & $24(49)$ & $4(22.2)$ & $28(41.8)$ \\
\hline Chapter 4 & Attitudes & & & & & & & \\
\hline $\mathrm{e} 450$ & Individual attitudes of & Facilitator & $18(50)$ & $16(100)^{\star \star}$ & $34(65.4)$ & $9(26.5)$ & $2(50)$ & $11(28.9)^{\dagger}$ \\
\hline & health professionals & Neither/nor & - & - & - & $1(2.9)$ & - & $1(2.6)$ \\
\hline & & Not applicable & $18(50)$ & - & $18(34.6)$ & $24(70.6)$ & $2(50)$ & $26(68.4)$ \\
\hline Chapter 5 & Services, systems and polic & & & & & & & \\
\hline e540 & Transportation services, & Facilitator & $21(50)$ & $8(53.3)^{\star}$ & $29(50.9)$ & $24(63.2)$ & $14(93.3)$ & $38(71.7)$ \\
\hline & systems and policies & Neither/nor & $15(35.7)$ & - & $15(26.3)$ & $6(15.8)$ & - & $6(11.3)$ \\
\hline & & Not applicable & $6(14.3)$ & $7(46.7)$ & $13(22.8)$ & $8(21.1)$ & $1(6.7)$ & $9(17)$ \\
\hline e570 & Social security services, & Facilitator & $48(98)$ & $18(100)$ & $66(98.5)$ & $46(95.8)$ & $17(94.4)$ & $63(95.5)$ \\
\hline & systems and policies & Neither/nor & $1(2)$ & - & $1(1.5)$ & $2(4.2)$ & $1(5.6)$ & $3(4.5)$ \\
\hline e580 & Health services, systems & Facilitator & $35(76.1)$ & $18(100)$ & $53(82.8)$ & $35(76.1)$ & $16(94.1)$ & $51(81)$ \\
\hline & and policies & Neither/nor & $8(17.4)$ & - & $8(12.5)$ & $10(21.7)$ & $1(5.9)$ & $11(17.5)$ \\
\hline & & Barrier & $3(6.5)$ & - & $3(4.7)$ & $1(2.2)$ & - & $1(1.5)$ \\
\hline
\end{tabular}

All values given indicate $n(\%)$.

$\mathrm{EH}$, early home participants; $\mathrm{LH}$, late home participants.

${ }^{\star} p<0.05,{ }^{\star \star} p<0.001\left(\chi^{2}\right.$-test); ${ }^{\dagger} p<0.05$ (Sign-test).

and speech and occupational therapists, early mobilisation, weekly multidisciplinary team meetings with the patient and continuing education for staff, patients, families and carers [26]. There is sufficient evidence for the benefit of stroke units as compared with care at a general ward [11]. Furthermore, the Swedish National Institute of Health and Welfare continuously updates its guidelines for national stroke care to ensure quality [27]. These efforts seem to be successful. However, at 3 months, fewer participants stated that health professionals and the system as being facilitators, and individual people even perceived health professionals and the health care system as being a barrier. An explanation here 
might be that, at 3 months, all participants had been discharged from a specialised stroke ward, and the community care service was responsible for their subsequent care. This might indicate that there is less well functioning care for stroke survivors in the community, perhaps as a result of less specialisation and a deficit in information transfer.

Eleven facilitators were identified but only one main barrier. At 6 weeks and at 3 months, about half of the participants described their physical geography as a barrier that hindered them from going out. Indeed, the region in which the participants lived (Göteborg region) is hilly and woody, where walkers are often confronted with uphill and wooded slopes.

In considering our results, it is important to keep the subjective characteristic of environment in mind. The same environmental factors may have different effects in people with different types and severity of impairments. Whether environmental factors are facilitators or barriers and the extent to which they are so depend on what people do in the context of the environment in which they live.

As this study is the first to categorise facilitators and barriers in the early post-stroke phase our results can only be compared with facilitators and barriers in a later phase. There are three studies in the field of stroke that have identified environmental facilitators and barriers. The most recent study considered chronic stroke survivors in the United States (Washington) [13]. Gray et al. [13] identified facilitators and barriers with FABS. Their findings are in accordance with our results. Assistive devices (both for mobility and at home), relationships and attitudes, and services and systems were perceived as facilitators. The second study investigated elderly Koreans (average age 71 years) with and without stroke [28]. Here, Han et al. [28] identified facilitators and barriers by applying CHIEF. They found stroke to be a significant predictor for barriers in services/assistance and policies, whereas our results indicate the opposite. Those who had suffered a more severe stroke (LH participants) more often mentioned health services and policies, and health professionals and transportation services as facilitators. This difference might be a result of the different health and welfare systems in the two countries. The third study identified facilitators and barriers in Canadian stroke survivors 6 months poststroke [6]. In this case, Rochette et al. [6] applied the MQE. Their findings showed that the six domains that are comparable with the five ICF chapters we investigated were perceived as both hindering and facilitating. Surprisingly, products and technology were only one-fourth more facilitating than hindering, whereas products and technology in our study were mainly seen as facilitators with some individual exceptions. This difference may depend on the different way the questions were posed. The MQE asks in the domain of 'aids, devices and technology' not only about their impact but also about the services related to technology access or maintenance. When our study participants named products and technology as facilitating, they focused on medicine, technical aids for mobility and assistive devices for daily living and not on services. It should be mentioned, however, that one-third of the study participants had problems moving around using equipment, as was shown in a corresponding study of the same stroke survivors on impairments and limitations (manuscript). Thus, the use of assistive devices for mobility was sometimes problematic but still generally facilitating. The overall positive statements about services, systems and policies as facilitators in our study were not confirmed by the findings of Rochette et al. [6]. Canadian stroke survivors perceived job and income security, and governmental and public services equally facilitating and hindering and equal opportunity and political orientation even more as hinders than facilitators. These differences obviously reflect the different policies and welfare systems in the two countries.

Comparing our results with findings in the literature is somewhat problematic, as the studies named above applied different scales (frequency and magnitude) to identify facilitators and barriers and the results were presented with scores. It can thus not be seen how many participants perceived the different environmental factors as facilitating or hindering, as can be seen in our study. On the other hand, our study gives no information about the extent to which a factor is a facilitator or barrier. The fact, that overwhelmingly facilitators and only one single barrier were identified by our study participants may seem amazing. A bias caused to social desirability can be questioned. This bias may be excluded for following reasons. First, the interviewer was not a provider of the participants' care. Second, most of the interviews were conducted at home in a 'neutral place'. Third, a common statement was: '...... despite the fact, that nowadays the health care system is commonly known to function poorly, I can absolutely not agree in my case...' Last but not least, our study sample seems to be an exceedingly positive group that does well, because their HRQoL was almost one-fifth higher than the HRQoL measured in other stroke study populations [29-32]. It is not simply that the participants had a relatively high $\mathrm{HRQoL}$, it seems also that there might be another explanatory variable for their HRQoL than functional status, as both $\mathrm{LH}$ and $\mathrm{EH}$ participants had about the same HRQoL at 3 months, despite the LH participants were more severely 
disabled. Other studies done in the early post-stroke phase have shown similar results. Madden et al. found only a poor association between HRQoL and functional status in the early post-stroke phase [33], and Rönning et al. showed that HRQoL was independent of disability 6 months post-stroke [34]. Considering the findings in the literature and our results, we hypothesise that HRQoL in the early post-stroke phase is not only related to functional status but also to environmental facilitators. Further research is needed.

\section{Conclusion}

Twelve ICF categories (within the 37 environmental categories of the Stroke ICF Core Set) were frequently named by the stroke survivors. Physical geography was the only environmental factor that was perceived as a great barrier. The environment of stroke survivors in Sweden is seen mainly as a facilitator in terms of the ICF chapters of social and health services, systems and policies, products and technology and support, relationships and attitudes. Participants showed a slight tendency to perceive facilitators as being less effective later in the rehabilitation chain. There may be a potential for optimising stroke care in this area. Furthermore, our results indicate that their might be an association between environmental facilitators and HRQoL in this early post-stroke phase. As our study is the first to consider environmental factors in the early post-stroke phase, there is a great need to carry out further studies to consolidate and compare findings. Further, comparisons of perceived facilitators and barriers in other countries and cultures may be able to provide information that can help to improve the quality of social and health services.

\section{Acknowledgements}

This research was supported by grants from the Swedish Research Council (VR K2002-27-VX14318-01A), the Wilhelm and Martina Lundgren Foundation, the Swedish Association of Persons with Neurological Disabilities (NHR), the Norrbacka-Eugenia Foundation, the Foundation of the Swedish Stroke Association, the John and Brit Wennerström Foundation of Neurological Research, Västra Götalands Handicap Committee, the Hjalmar Svensson Foundation, the Greta and Einar Asker Foundation and Praktikertjänst AB. We acknowledge the members of the ICF Research Branch, Munich, for their service regarding ICF Core Sets.

\section{References}

1. Rittman M, Faircloth C, Boylstein C, Gubrium J, Williams C, Van Puymbroeck $M$, et al. The experience of time in the transition from hospital to home following stroke. J Rehabil Res Dev 2004;41:259-268.

2. Cott C, Wiles R, Devitt R. Continuity, transition and participation: preparing clients for life in the community post-stroke. Disabil Rehabil 2007;29:1566-1575.

3. Institute of Medicine. Enabling America: assessing the role of rehabilitation science and engineering. Washington (DC): National Academic Press, 1997.

4. World Health Organization. International classification of functioning, disability and health: ICF. Geneva: World Health Organization, 2001.

5. Fougeyrollas P. Documenting environmental factors for preventing the handicap creation process. Quebec contributions relating to the ICIDH and social participation of people with functional differences. Disabil Rehabil 1995;17:145-153.

6. Rochette A, Desrosiers J, Noreau L. Association between personal and environmental factors and the occurrence of handicap situations following a stroke. Disabil Rehabil 2001;23:559-569.

7. Gosman-Hedström G, Claesson L, Blomstrand C. Assistive devices in elderly people after stroke: a longitudinal, randomized study - the Göteborg $70+$ stroke study. Scand J Occup Ther 2002;9:109-118.

8. Paolucci S, Bragoni M, Coiro P, de Angelis D, Fusco F, Morelli D, et al. Quantification of the probability of reaching mobility independence at discharge from a rehabilitation hospital in non-walking early ischemic stroke patients: a multivariate study. Cerebrovasc Dis 2008;26:16-22.

9. Glass T, Matchar D, Belyea M, Feussner J. Impact of social support on outcome in first stroke. Stroke 1993;24:64-70.

10. Tsouna-Hadjis E, Vemmos $\mathrm{K}$, Zakopoulos $\mathrm{N}$, Stamatelopoulos S. First-stroke recovery process: the role of family social support. Arch Phys Med Rehabil 2000;81: 881-887.

11. Stroke Unit Trialists' Collaboration. Organised inpatient (stroke unit) care for stroke. Cochrane Database Syst Rev 2001;(3):CD000197.

12. Whiteneck G, Harrison-Felix C, Mellick D, Brooks C, Charlifue S, Gerhart K. Quantifying environmental factors: a measure of physical, attitudinal, service, productivity, and policy barriers. Arch Phys Med Rehabil 2004;85:13241335.

13. Gray DB, Hollingsworth HH, Stark S, Morgan KA. A subjective measure of environmental facilitators and barriers to participation for people with mobility limitations. Disabil Rehabil 2008;30:434-457.

14. Geyh S, Cieza A, Schouten J, Dickson H, Frommelt P, Omar Z, et al. ICF Core Sets for stroke. J Rehabil Med 2004;(Suppl. 44):135-141.

15. Ewert T, Grill E, Bartholomeyczik S, Finger M, Mokrusch T, Kostanjsek N, et al. ICF core set for patients with neurological conditions in the acute hospital. Disabil Rehabil 2005;27:367373.

16. Stier-Jamer M, Grill E, Ewert T, Bartholomeyczik S, Finger $\mathrm{M}$, Mokrusch $\mathrm{T}$, et al. ICF core set for patients with neurological conditions in early post-acute rehabilitation facilities. Disabil Rehabil 2005;27:389-395.

17. Jorgensen H, Nakayama H, Raaschou H, Vive-Larsen J, Stoier $\mathrm{M}$, Olsen T. Outcome and time course of recovery in stroke. Part II: time course of recovery. The Copenhagen stroke study. Arch Phys Med Rehabil 1995;76:406-412.

18. Kwakkel G, Kollen B, Twisk J. Impact of time on improvement of outcome after stroke. Stroke 2006;37:23482353. 
19. World Health Organization. Stroke - 1989. Recommendations on stroke prevention, diagnosis, and therapy. Report of the WHO task force on stroke and other cerebrovascular disorders. Stroke 1989;20:1407-1431.

20. ICF Research Branch of WHO CC F IC (DIMDI), Institute for Health and Rehabilitation Sciences, Ludwig-Maximilian University. ICF Core Sets multicenter international validation study. Ludwig-Maximilian University, Germany. Available from http://wwwicf-research-branchorg/research/validation studyhtm. 2006.

21. Lai SM, Duncan PW. Stroke recovery profile and the modified Rankin assessment. Neuroepidemiology 2001;20:26-30.

22. Wilson J, Hareendran A, Hendry A, Potter J, Bone I, Muir K. Reliability of the modified Rankin scale across multiple raters: benefits of a structured interview. Stroke 2005;36: 777-781.

23. Dorman P, Waddell F, Slattery J, Dennis M, Sandercock P. Is the EuroQol a valid measure of health-related quality of life after stroke? Stroke 1997;28:1876-1882.

24. Rabin R, de Charro F. EQ-5D: a measure of health status from the EuroQol group. Ann Med 2001;33:337-343.

25. Chakravarti IM, Laha RG, Roy J. Handbook of methods of applied statistics. Vol. 1. New York: Wiley, 1967; pp 392-394.

26. Kjellström T, Norrving B, Shatchkute A. Helsinborg declaration 2006 on European stroke strategies. Cerebrovasc Dis 2007;23:229-241.

27. Nationella riktlinjer för strokesjukvård. Stockholm: Socialstyrelsen; 2006. htp://www.socialstyrelsen.se/Amnesord/halso_ sjuk/riktlinjer/stroke
28. Han C, Yajima Y, Lee E, Nakajima K, Meguro M, Kohzuki $M$. Validity and utility of the Craig Hospital inventory of environmental factors for Korean community - dwelling elderly with or without stroke. Tohoku J Exp Med 2005;206:41-49.

29. Barton G, Sach T, Doherty M, Avery A, Jenkinson C, Muir $\mathrm{K}$. An assessment of the discriminative ability of the EQ$5 \mathrm{D}_{\text {index }}, \mathrm{SF}-6 \mathrm{D}$, and EQ VAS, using sociodemographic factors and clinical conditions. Eur J Health Econ 2008;9: 237-249.

30. Darlington A, Dippel D, Ribbers G, van Balen R, Passchier J, Busschbach J. Coping strategies as determinants of quality of life in stroke patients: a longitudinal study. Cerebrovasc Dis. 2007;23:401-407.

31. Lubetkin E, Jia H, Franks P, Gold M. Relationship among sociodemographic factors, clinical conditions, and healthrelated quality of life: examining the EQ-5D in the U.S. general population. Qual Life Res 2005;14:2187-2196.

32. Salbach N, Mayo N, Robichaud-Ekstrand S, Hanley J, Richards C, Wood-Dauphinee S. Balance self-efficacy and its relevance to physical function and perceived health status after stroke. Arch Phys Med Rehabil 2006;87:364-370.

33. Madden S, Hopman W, Bagg S, Verner J, O'Callaghan C. Functional status and health-related quality of life during inpatient stroke rehabilitation. Am J Phys Med Rehabil 2006;6:831-838.

34. Rönning O, Stavem K. Determinants of change in quality of life from 1 to 6 months following acute stroke. Cerebrovasc Dis 2008;25:67-73. 